Mental health recovery and nature: How social and personal dynamics are important Matthew Adams* and Julie Morgan

Both: School of Applied Social Science, University of Brighton, Falmer, BN1 9PH, UK Email: Matthew.Adams@brighton.ac.uk; J.Morgan2@brighton.ac.uk

*Correspondence should be addressed to Dr Matthew Adams, School of Applied Social Science, Mayfield House, University of Brighton, Falmer, BN1 9PH, UK. Email: Matthew.Adams@brighton.ac.uk

NOTE: This is author's accepted, pre-proof, pre-publication version. Published version available here: http://online.liebertpub.com/doi/full/10.1089/eco.2017.0032

To cite this article: Adams M. \& Morgan J. (2018) Mental Health Recovery and Nature: How Social and Personal Dynamics Are Important, Ecopsychology. January 2018, ahead of print https://doi.org/10.1089/eco.2017.0032

\title{
Mental health recovery and nature: How social and personal dynamics are important
}

\begin{abstract}
A number of projects support people with mental health difficulties through connecting them with nature. Their popularity reflects a growing evidence-base recognising that being in nature can have significant benefits for wellbeing. This study reports on the social and psychological benefits of being involved in a specific programme that aims to help people with mental ill health experience a connection with nature in a supportive social group. The experiences of 9 different groups of participants $(N=87)$ over three years of a nature-based programme were examined. A thematic analysis of participants' accounts of their experiences revealed the specific personal and social benefits to be gained from participation in a naturebased programme. Four key interrelated themes emerged: escape, being present, social contact and personal growth. These findings suggest nature-based recovery is aided by the mutually reinforcing dynamics of being in nature, shared recognition and support through contact with others, and greater understanding of the self. The implications of these findings for a recovery model of mental health are discussed.
\end{abstract}

\section{Key words}

Belonging, identity, mental health, nature-connectedness, recovery, social contact 


\section{Introduction}

There is growing recognition that the natural environment can promote mental health and wellbeing - a position which has been long championed, challenged and developed in research published in this journal (e.g. Chalquist, 2009; Iwata et al., 2016; Korpela et al. 2016; Paidas, 2011). Mental health charities such as MIND increasingly advocate naturebased interventions as an alternative or additional form of treatment for a range of mental health issues and in supporting mental health more generally (e.g. Peacock, Hine \& Pretty, 2007), echoing growing calls from scholarship and campaigning bodies internationally (e.g. Friends of the Earth, 2017; World Health Organization, 2005). ${ }^{1}$ In summarising the existing evidence base, a recent report commissioned by Natural England for the UK government noted three key components that characterise successful nature-based interventions: the natural environment; meaningful activities; and the social context (Bragg and Atkins, 2016). In terms of the third element, although it was highlighted in this report, and others (e.g. Bragg, Wood, \& Barton, 2013) as key, what is meant by the term is not articulated in any detail.

Turning to specific examples of empirical research, numerous studies have cited social contact as one of a number of beneficial aspects of nature-based activities of different kinds (e.g. Gonzalez et al. 2011; Parkinson et al. 2011; Rappe et al. 2008; Webber et al. 2015). In their review of gardening as a mental health intervention, for example, Clatworthy et al. note that such interventions are 'usually social', in that they provide opportunities for interaction, and may, therefore, 'play a key role in promoting a sense of belonging and enhancing social inclusion for people experiencing mental health difficulties' (2013, p. 215). Webber et al. note that 'an affirming and inclusive social milieu' is reported as contributing to the well-being benefits of social and therapeutic horticulture for individuals with mental health difficulties (2015, p. 20). In their own study, Webber et al briefly note connectedness to 'the diverse community on the allotment' as a perceived benefit (p. 25); though gardening, in this context 'may also operate as an escape from social interactions and pressures' (p. 26; see also Hawkins et al. 2013). Existing work, in sum, suggests that social contact is a common aspect of at least some forms of nature-based intervention, and often beneficial, though not unequivocally so. However, it is rarely explored in further empirical detail, such as in terms of what it might mean from the perspective of participants.

Paying closer empirical attention to the social dimension of nature-based interventions needs to be accompanied by a theoretical framework for making sense of how an embodied connection to nature, social contact and psychological processes interrelate in the experience of effective nature-based interventions. There is potential here to learn from 'recovery' models of mental health and illness, which are psychosocial in orientation, with an emphasis on healing environments. There are numerous iterations of a 'recovery model', but broadly speaking they eschew medical framings of the concept of recovery as being 'cured' or 'symptom-fee' (Tew, 2013). Recovery from mental illness is understood as gradual and nonlinear, as a struggle, and as an idiosyncratic, active process; one that may involve professional interventions but is also aided by supportive and healing environments (Leamy et al. 2011; Topor, Borg, Di Girolamo, \& Davidson, 2011).

As Tew asserts, 'conceived in this way, recovery is both a personal and a social process - in which resolution of internal distress takes place alongside social reengagement in 
ways that may be mutually reinforcing' (Tew, 2013, p. 361). Leamy et al.'s (2011) metaanalysis of research drawing on a recovery model offers further detail of the psychosocial process described by Tew. They discovered a shared emphasis on a number of interlinking processes considered key to healing environments: social connectedness; hope and optimism about the future; a positive sense of identity; meaning in life; and empowerment. In the discussion, we will consider how our participants' responses support this psychosocial framing of recovery, and whether a conceptualisation of recovery 'capital' can additionally incorporate the healing role of the natural environment.

The research reported here is based on a project designed to support people with experiences of mental illness, particularly depression and anxiety, by providing regular connection with nature in a safe, supportive group environment. Participants were recruited as part of a small closed group (7-12 people), who met weekly, for a whole day, as part of an 8-week programme (referred to as a 'season'). The group gathered in the South Downs National Park, which traverses Sussex and Hampshire in the south of England. Transport to and from the location and food and drink was provided for the group. Each day was structured around an initial 'check-in' and a final 'check-out' where people were free to share thoughts and reflect on how they were feeling. A number of activities were made available across a season, thanks in part to the input from the National Trust - a conservation organization and governing body of protected sites for most of the UK. These include guided nature walks, conservation tasks, green woodworking, wild food foraging, shepherding, mindfulness and creative activities. Members of the group inputted into discussion of what activities they would like to undertake across a season. Importantly, there was also flexibility on each day - people were free to engage in activities, walk, talk or simply be. Formal support was provided by two project staff and two additional trained volunteers.

Our research examined the experiences of different groups of participants across 9 seasons of the programme, over 3 years. It offered a relatively rare opportunity, judging by the literature to date, to follow iterations of a nature-based project over a significant period of time. Our primary aim was to explore the ways in which people with experiences of psychological distress may benefit from participation in a structured nature-based programme through a close analysis of their descriptions of their experiences within the programme. To address this aim we asked two research questions:

1. How do participants in a nature-based intervention describe the benefits of participation?

2. To what extent do social and personal dynamics feature in participants' accounts of involvement?

\section{Method}

\section{Participants}

We analysed the responses of 87 people (61 females and 26 males) who had taken part in one full season of the project. These responses covered 9 seasons over 3 years (there were a group of 7 to 12 people in each season). The mean age of those who participated was 43.88 years $(S D=11.69$, minimum age $=20$, maximum age $=73)$. People who chose to join the project were either referred by a mental healthcare provider (e.g., a psychiatrist, 
psychologist, counsellor), or responded to an advertisement posted in a local community directory. Following this initial contact stage, an informal interview took place with members of the project team, where the intervention was explained further.

\section{Procedure}

Our research questions were aimed at understanding the experience of participating in a nature-based programme from the perspective of those involved. We utilised a relatively low-intensity means of qualitative data collection: a combination of semi-structured survey questions directed at people's experiences of the project, and more open-ended but optional testimony that formed a handful of case-studies. The use of qualitative approaches is common in a range of topics relating to health care, interventions and promotion, including mental health (e.g. Joffe, 2012; Tong, Sainsbury \& Craig. 2007; Weare and Nind, 2011). Whilst we were committed to exploring participants' viewpoints, we also aimed to conduct our research with minimum disruption to the context in question, a common concern in qualitative approaches (Speziale, Streubert \& Carpenter, 2007); and to avoid over-burdening participants, many of whom have had extensive experience of being subjected to monitoring and evaluation in relation to their experiences of psychological distress. The survey questions asked participants to comment on any impact the project had on any aspect of wellbeing if at all, on skills developed and learning experiences while participating, and on expectations for the future. Testimonies involved participants' writing about any aspect of the project in unstructured blog/diary form in as much detail as they liked.

\section{Data analysis}

Thematic analysis was considered the most suitable method for making sense of this data. As this study was exploratory, we were keen for theory to emerge from the phases of thematic analysis and for it to be traceable back to that analysis, hence we adopted an inductive approach to our interpretation and analysis, broadly influenced by grounded theory (Glaser and Strauss, 2009; Tan, 2010). Our main concern was fidelity to participants' identification and articulation of their experiences of the project. We adopted Braun and Clarke's (2006) approach to thematic analysis comprising of six phases: familiarization with the data; coding; searching for themes; reviewing themes; defining and naming themes; writing up.

The authors initially familiarized themselves with, and coded, the data separately. We did this by transcribing and collating all comments (most were handwritten; some were already word processed) - which in itself was a process of familiarization. We then embarked individually on a process of pulling out comments and pooling them together if they appeared to share a similar emphasis. Comments were arranged visually - using a large space, gradually clustering similar phrases, expressions and orientation together. At this stage of coding, themes were not named, as the process was purposefully intuitive and open. Distinct themes gradually emerged, were tentatively named, and literally encircled, giving the appearance of a Venn diagram. Comments often fitted more than one theme or fell between them - the circles were allowed to overlap, and this is where such comments were placed. Both authors then worked collaboratively by bringing together their individual visualisations 
of themes, creating a shared diagram. Through a process of dialogue and deliberation we reviewed the themes, gradually sharpened their focus, and began the process of articulating each of them and points of overlap. By following these steps, our approach roughly mapped on to the six stages of analysis as posited by Braun and Clarke.

\section{Results}

Following the thematic analysis procedures described above, four general themes were identified in response to our research questions - escape, being present, social contact and personal growth - which we tentatively frame collectively as interlinking elements of recovery. Together they provide an account of participants in a nature-based intervention describe the benefits of participation; and the relative and related emphasis on the social and personal dynamics involved. Each theme is explored in turn, followed by a discussion of points of overlap and intersection. Pseudonyms are used for all participants, followed by the season (S) number (e.g. S1); and, where appropriate, identified as a case study (CS).

\section{Escape}

When describing the perceived benefits of involvement in the project, explanations were closely tied with what those involved perceived themselves to be away from, as much as what they were entering into or connecting with - clearly echoing the importance of 'being away' - a 'temporary escape from one's usual setting or situation' for an environment to be genuinely 'restorative' (Greenleaf, Bryant \& Pollock, 2013, p. 166; Kaplan and Kaplan, 1989). Members of a season described the importance of escaping particular 'external' environments - built, urban and the 'familiar' or 'everyday' (including mental health services); but also 'internal' environments - one's 'normal' self, thought processes and emotions. ${ }^{2}$ For example, for Wesley 'taking time out from everyday life has helped me discover what are some of my needs to improve my wellbeing' (S7); whilst Joanna valued how she was able to 'step outside of being always in my head. Being in the moment' (S9).

Participants were able to articulate this 'escape' as a dynamic process that took place during their time spent in the natural environment:

'Often when I got to the farm I was very emotional and quite down at first, just sinking into the place with a huge sense of relief - a time for me, to just be me and not do battle with whatever issue was centre stage at that time in my life at home. And then very soon after I found myself feeling quite different. The release of my emotions was allowed, I felt calmer than I had done in ages and I laughed, felt happy and healthy' (Miriam, CS, S8)

This was a process that involved escaping from, be it an aspect of themselves, or familiar places and routines, but also an escape into something, which leads us to the second of our themes.

\section{Being present}

Participants often described what they were escaping into with rich and evocative descriptions. Invariably these descriptions reflected some form of positive nature connection. Again though, while the literature to date has consistently established this, it has rarely 
explored this beyond the nominal indices of wellbeing or restorative environments. Here we found that people tended to elaborate the value of their connection with nature as a heightened sense of being present and aware in and of the moment: 'Taking notice of the nature around me everyday' (Sarah, S8); in the moment and/or in one's body: 'tak[ing] me into my body and out of my head' (Ivor, S3). Audrey elaborates here:

'My frantically over-working, poor old worn-out mind got a break. I couldn't think about anything else when I was searching for fossils on the shoreline, being guided in an ecotherapeutic meditation or fighting recalcitrant greenery into a Christmas wreath. Those moments gradually started to add up, giving me what months of CBT hadn't: the ability to switch off the endless self-criticism and terrifying thoughts, if only for a bit (Audrey, CS, S7).

People's talk revealed the importance of a sense of escape from, but, equally, an escape into the present, as a vital aspect of positive nature-connection, and as a basis for recovery.

\section{Social contact}

The benefits of contact with others in the group were articulated in two discernible ways: in terms of the positive benefits of being with others in the moment, i.e. whilst part of the group; but also as a resource to draw upon more generally, when with others. Regarding the first point, participants stated simply that they enjoyed and valued sharing positive experiences with others, e.g. 'being in nature with such an accepting, supportive, kind and beautiful group' (Wesley, S7). Mutual recognition within the group was regularly emphasised as a positive outcome of social contact in the moment, evident in statements such as the following:

[I] enjoyed meeting other people who had a mutual understanding of what it's like to suffer from mental health conditions. It was helpful to be with people who understood if you were feeling unwell, tearful or 'delicate'. You could be yourself and not have to pretend. (Christine, S3)

In the case study testimonies, this sense of recognition, acceptance and empathy was elaborated upon extensively, for example:

'For the first time in my life I was spending time with people that not only understood my struggles but empathised with them. I was able to be authentic and say I was struggling and receive support from my peers, which was an almost entirely new experience for me. I was able to let down my guard, let people in and learn about myself' (Harry, CS, S7).

The role of mutual recognition here supports the link between perceived mutual support, group identification and wellbeing in the wider literature (e.g., Corrigan, Sokol, \& Rüsch, 2013).

The second aspect of this theme extends our understanding of these links. In our findings, the benefits of the experiences of positive social contact and support were perceived 
to have had a more generalised impact on participants' abilities to be in a group. This was expressed in terms of less negative feelings such as isolation, awkwardness and anxiety in group situations and at the prospect of social contact: 'I feel less shy around new people' (Carrie, S5); '[I] feel less self-conscious... less awkward about speaking up/out' (Ivor, S3). Relatedly, statements also included assertions about more positive feelings regarding an increased willingness and ability to engage in social contact as a result of positive social experiences during the interventions: 'I feel a lot more comfortable in group situations now' (Lily, S3); 'it has given me a great boost to socialise and be part of a group of mixed people... made me more positive about meeting people' (Liam, S2).

\section{Personal growth}

In the fourth and final of our themes, participants placed a great deal of emphasis upon experiences of personal growth, particularly in terms of how the intervention provides a greater capacity for self-reflection, self-acceptance and a future-orientation, often in relation to the themes we have already discussed. Here we have the opportunity to elaborate on more prosaic assertions of increased wellbeing in standard outcome measures. Whilst this theme may appear to be distinct from the theme of social contact, we will go on to suggest that both themes are in fact mutually implicated in one another.

An avowed improvement in participants' ability to self-reflect, and explore new or alternative perceptions of the self, was evident in many of the accounts provided. Through self-reflective responses, people indicated an increased openness to acknowledging and accepting different aspects of the self, and a willingness to explore the nature of negative feelings without making judgments about the self:

'[the intervention] taught me (more than months of CBT) how to pause and compassionately, honestly and positively reflect on how I'm feeling and what makes me feel better' (Euan, S1)

'[the intervention] has helped me get in touch with how I have been affected by my mental health, something that I tended to run away from before - until my depression or anxiety would get so bad I'd have to take notice of it!' (Miriam, CS, S8)

Descriptions of greater understanding of the self were often presented as a first step towards overcoming existing problems and difficulties. People described how self-reflection becomes a resource for a more constructive and adaptive way of thinking about the self, helping them understand their own needs, and becoming more self-accepting. In fact, a greater degree of self-acceptance was also elaborated upon explicitly, to the extent that we identified it as a distinct subtheme, contributing to a broader sense of personal growth.

People frequently made reference to their experience of self-acceptance as a direct result of participation, and often as an outcome of the self-reflection described above. In particular, many of those involved remarked on a notable shift in their attitudes towards both their past and present struggles, and further acknowledged a non-judgmental acceptance of these vulnerabilities: 
'[the project] allowed me to accept myself and my limitations without beating myself up when I feel tired or unable to achieve something' (Mick, S4)

'...accepting that I'm an introverted person but that doesn't mean I can't form friendships' (Andy, S7)

In the wider literature, self-acceptance is more generally associated with a wide range of positive aspects of mental health (e.g. Chamberlain and Haaga, 2001; MacInnes, 2006). Here, group members explicitly acknowledged how self-acceptance enabled them to develop a healthier and more positive relationship with their own sense of self, e.g. 'I feel more integrated as a person, more able to be all of my whole self and not hide away some aspects of myself' (Miriam, CS, S8).

Finally, experiences of self-reflection and self-acceptance appear to combine as a capacity for resilience and confidence, as reflected in our final sub-theme, future-orientation. Participants' expectations for the future were often stated in terms of the resources that the project had provided for them going forward, and formed the basis for a more positive outlook. This sense of resilience was expressed in terms of the present - how people were coping in the here and now - but also for projecting a more resilient self into the future:

'I feel much more positive/confident and better equipped to meet life's challenges' (EW, S3)

'I draw on my experiences from [the intervention] on many occasions to feel stronger' (RS S7)

'There is no magic wand to wave over my life but what the project has provided is a sprinkling of magic I will find ways to use sparingly and when in greatest need' (Carrie, S5)

It should be noted at this stage that in the fuller context of responses, some or all of the themes identified here overlapped or intersected extensively. Descriptions of selfacceptance were interwoven with statements about acceptance from the group; or a sense of belonging was associated with greater care for one's self, which were often in turn reflected in hopeful statements about the future. Crucially, nature connectedness was identified as a key theme, and experiences of nature and place were also incorporated into this overlap:

'I felt the group and the place very much held me, and I wasn't expected to be anything other than how I was feeling and what I was able to do or not do on that day' (Miriam, CS, S8).

Although admittedly speculative, Miriam's comment, and numerous others, speak to an attachment to place - to being 'held' by it. This chimes with ecopsychological accounts of nature as potentially providing secure attachments and holding environments (Jordan, 2009), 
that parallel, perhaps even mutually facilitate, those connections to people, and are considered vital for healthy human development (Winnicott, 1965; 1974). We revisit this possibility in the discussion. Pervaded by self-reflection, a growing sense of connectedness to nature is articulated as impacting upon the way social contact is sought. The articulation of all or most themes as interrelated suggests the benefits of social and nature contact are mutually reinforcing. We also consider some of the possible reasons for this close interrelationship in the discussion.

\section{Discussion}

This study has explored how individuals with experiences of psychological distress, often including diagnoses of mental illness, described their participation in an 8-week season of a nature-based intervention, as part of a group. Responses from multiple seasons over 3 years were considered. Our findings build on existing research that recognises the value of nature-based interventions for mental health by showing why social contact within such programmes is important, and what participants specifically gain from the programme for their psychological wellbeing. In addressing our key research questions, we found that participants overwhelmingly emphasised the positive benefits of their involvement in terms of both the social benefits (in particular, the value of shared experience and mutual understanding with others in the group) and the personal benefits (as a way to re-focus and reflect, taking experiences forward in a way that could help to build resilience). In a thematic analysis of participants' accounts of their experiences, four key interrelated themes emerged within a broad framework of interlinking elements of recovery: an escape (from everyday, often problematic environments, including routines, places, states of mind and ways of feeling); being present (in the moment, in nature); social contact (enjoyed in the moment, and more generally as a model for future social contact); and personal growth (incorporating a greater capacity for self-reflection, self-acceptance and future-orientation). Many of these themes were interrelated in participant's responses.

In the following discussion, we consider how our findings relate to the recovery model of mental illness outlined in the introduction. Leamy et al.'s (2011) recent metaanalysis of research utilising a recovery model identified five key and interlinking processes involved in recovery: connectedness (peer support and support groups, relationships, being part of the community); hope and optimism about the future; identity (overcoming stigma, rebuilding/redefining positive sense of identity); meaning in life (meaning of mental illness experiences, meaningful life and social roles); and empowerment (control over life, personal responsibility). To some extent our findings chime with these five processes - in fact each of them is clearly discernible in the way the participants talk about their involvement with the project.

Perhaps the clearest link is between 'connectedness' and our theme of social contact. Previous research has identified social contact or connection as a key outcome of naturebased interventions (e.g. Bragg and Atkins, 2016). However, additional exploration of the social dimension is rarely unpacked further. Here we addressed participants' own understandings of what social contact means for them, and why and how the contingencies of natural settings interrelate with positive social experiences. We found two variations on the theme of the benefits of social contact, that combined speak to and flesh out other recovery 
processes highlighted by Leamy et al: identity, meaning and hope for the future are arguably all strengthened by positive experiences of being in a group, and an improved ability to experience and imagine being with others more generally. In noting the interrelatedness of themes in the way participants responded, it is arguably the other themes - a sense of escape, feeling present and 'held' by the natural environment - that nurtured novel and beneficial forms of social contact; suggesting that a fuller consideration of natural settings might broaden and enhance conceptual models of the key processes of recovery.

Another key process identified by Leamy et al, 'hope and optimism about the future', is also considered to be one of the key indicators of recovery-oriented practice in related conceptual frameworks (e.g. Bonney and Stickley, 2008; Resnick et al. 2005). It relates closely to our theme of personal growth. In fact, future-orientation was identified as a salient element of personal growth in participants' own descriptions, alongside, and facilitated by, a greater capacity for self-reflection and self-acceptance. These processes are also arguably central to the development of self-compassion and the rebuilding of a positive sense of identity (Neff, 2003) - another key process of recovery identified by Leamy et al. Developing interventions which facilitate these capacities is likely to bolster opportunities to develop hope and optimism about the future and a positive sense of identity.

Other processes identified as essential to recovery are supported by our findings. Experiences of overcoming stigma as an aspect of positive identity is evident in the way participants described the benefits of social contact in terms of feeling acknowledged and recognised beyond diagnostic labels. The ramifications of feeling accepted by a group described here support associations between peer/social support and indicators of wellbeing, mental health and recovery from mental health difficulties in the wider literature (e.g., Tew, 2013), especially for minority and/or stigmatised groups (e.g., Bockting, Miner, Swinburne Romine, Hamilton, \& Coleman, 2013; Fazel, Reed, Panter-Brick, \& Stein, 2012; FredriksenGoldsen et al. 2013; Harbeck, 2014).

A greater sense of meaning in life is arguably an overarching narrative evident across a number of our themes, especially in terms of talk about a more positive sense of possibility, individually and socially, moving forward. Potentially therefore, the recovery model provides a way of conceptualising the interrelationship of psychological and social benefits of naturebased projects like the one focused on here. However, whilst the themes of social contact and personal growth in particular reflect the emphasis on social connection and personal factors in existing frameworks, our themes of escape and being present encourage a broader conceptualisation of recovery. These are potentially important processes in their own right (see for example Macpherson et al. 2009); but as constituent aspects of being in nature, they also speak more explicitly to the potential role of the natural environment in recovery.

Might a recovery model have the potential to incorporate natural environments as intersecting with social and community dynamics in encouraging recovery? The allied concept of 'recovery capital', which has recently emerged in mental health and recovery literature, particularly in the field of addiction and substance misuse, suggests it might (e.g. Cloud \& Granfield, 2008; White \& Cloud, 2008). Recovery capital is 'a way of conceptualising factors that may be important in enabling people to make a sustainable recovery from currently disabling mental health difficulties' (Tew, 2013, p. 362). It is embedded in the development of the survivor movement and recovery-oriented practice, and 
as the name suggests, acknowledges the intersection of different forms of 'capital' (economic, social, relationship, identity, personal) as important for recovery (Tew, 2011; Schuller, Bynner, \& Feinstein, 2004).

The work of Tew and others points to the significance of space being available for this reworking of social connectedness and personal autonomy. However temporary and imperfect, nature-based projects modelled in similar ways to the one reviewed here arguably provide such a space. Those involved encounter new groups of people, forming supportive communities, relatively free from the usual trappings of everyday life. There is then the opportunity to negotiate a more valued and satisfying place for one's self, vitally, amidst others, however tentative. We might add, more speculatively, that natural spaces potentially afford a deeper sense of belonging and identification that is beyond human. There is a different tradition of work that emphasizes how nonhuman nature 'holds' human beings, but there is also a growing psychological interest in categories of belonging and community that involve nonhuman nature and their effects (e.g. Abell, 2013; Frantz and Mayer, 2014; Vining, 2003). In this context, it is certainly plausible that nature-connectedness, social contact and opportunities for personal growth work as mutually reinforcing processes that encourage recovery from chronic experiences of sadness and distress.

There are some limitations to the present study. We have not made an attempt here to differentiate our findings in terms of potential individual and demographic differences; for example, differences between group members in terms of any mental illness diagnosis or ongoing treatment. Although participants frequently made positive statements about mutual recognition and shared understanding of mental health difficulties within their group, we acknowledge that each individual's own particular history could potentially affect their engagement with, and the outcome from, the project. We did not consider the effects of a nature-based intervention in comparison to a group experiencing an alternative or no intervention. This was never our intention - what we offer here is an exploratory account of a particular project, with a strong emphasis on how it was experienced by those involved; and there are numerous precedents for studies of specific interventions (e.g. Wilson et al. 2010; 2011). That said, there is no reason why further studies could not attempt to compare a nature-based intervention with more traditional treatment methods; though it is worth noting the difficulty of making genuine comparisons in an area where so many complex variables are at play - much more than simply 'indoors' versus 'outdoors' (Adams and Jordan, 2016).

The current findings have important implications for future research. In the context of a social recovery model, and the related concept of recovery capital, described above, there is clearly scope for theory and research which incorporates the value of nature-based interventions in recovery more explicitly. From a critical psychological orientation, it is also important that the insights derived from a greater focus on social, cultural and structural factors involved in mental ill-health, recovery and wellbeing should be transferred into research exploring the value of nature-based interventions (Adams, 2014). We should not understand the relationship between individuals and nature as somehow immune to or 'outside' of these factors. Instead we should seek to explore how nature-based interventions intersect with, reflect or challenge social, cultural and structural dynamics.

Given that the nature-based programme described here was centred around voluntary participation in a range of nature-based activities, future research should focus on further 
establishing what aspects of these activities were beneficial for those who engaged in them. Our findings add to a growing awareness of the value of such activities for mental health. However, it is important to note that health benefits are not necessarily exclusively related to activities that take place in natural environments. Indeed, the positive impact on wellbeing of creative arts activities offered in a social community setting has been well documented (see Clift, 2012). For example, Argyle and Bolton (2005) found that multiple therapeutic benefits could be gained from the provision of art activity sessions for vulnerable mental health community groups. Taken together with the current findings, it seems that engagement with activities, perhaps through the sense of self-agency and achievement these activities provide, may play a key role in the recovery process. Future research may elucidate whether it is something gained from participation in the activity itself, or the social nature of the activities that people find particularly beneficial.

Finally, research should focus on the role of nature in maintaining and improving wellbeing for people more generally, as part of a meaningful social and personal life, not just for those with a history of mental illness diagnoses or experiences of psychological distress. The value of nature-based interventions lies in their contribution to public health, as an 'upstream' community-based service (Maller et al. 2006), at least as much as a resource for individual recovery, a fact embraced by a growing number of national and international

public health bodies. ${ }^{3}$ These are pertinent issues in a social and political context where increased recognition of the benefits of access to natural settings occurs whilst nature as a place for human and nonhuman survival and flourishing is in retreat.

\section{References}

Abell, J. (2013). Volunteering to help conserve endangered species: An identity approach to human-animal relationships. Journal of Community and Applied Social Psychology, 23, 157170. doi: $10.1002 /$ casp. 2114

Adams, M. (2014). Approaching Nature, 'Sustainability' and Ecological Crises from a Critical Social Psychological Perspective. Social \& Personality Psychology Compass, 8, 251 262. doi: $10.1111 / \mathrm{spc} 3.12104$

Adams, M. \& Jordan, M. (2016). Growing together: nature connectedness, belonging and social identity in a mental health ecotherapy programme. In M. Jordan \& Jo. Hinds (Eds.) Ecotherapy: theory, research and practice. Basingstoke: Palgrave. Pp. 122-136.

Argyle, E. \& Bolton, G. (2005). Art in the community for potentially vulnerable mental health groups. Health Education, 105, 340-354.

Barton, J., \& Pretty, J. (2010). What is the best dose of nature and green exercise for improving mental health? A multi-study analysis. Environmental Science \& Technology, 44, 3947-3955. doi: 10.1021/es903183r 
Bockting, W. O., Miner, M. H., Swinburne Romine, R. E., Hamilton, A., \& Coleman, E. (2013). Stigma, mental health, and resilience in an online sample of the US transgender population. American Journal of Public Health, 103, 943-951. doi:

10.2105/AJPH.2013.301241

Bonney, S., \& Stickley, T. (2008). Recovery and mental health: a review of the British literature. Journal of Psychiatric and Mental Health Nursing, 15(2), 140-153.

Braun, V., \& Clarke, V. (2006). Using thematic analysis in psychology. Qualitative Research in Psychology, 3, 77-101. doi:10.1191/1478088706qp063oa

Bragg, R., \& Atkins, G. (2016). A Review of Nature-Based Interventions for Mental Health Care. Natural England Commissioned Reports, Number204. Retrieved from http://publications.naturalengland.org.uk/publication/4513819616346112

Bragg, R., Wood, C., \& Barton, J. (2013). Ecominds: effects on mental wellbeing. MIND, 15, 4BQ. Retrieved from https://www.mind.org.uk/media/354166/Ecominds-effects-on-mentalwellbeing-evaluation-report.pdf

Chalquist, C. (2009). A look at the ecotherapy research evidence. Ecopsychology, 1(2), 6474.

Chamberlain, J. M., \& Haaga, D. A. (2001). Unconditional self-acceptance and psychological health. Journal of Rational-Emotive and Cognitive-Behavior Therapy, 19, 163-176. doi: 10.1023/A:1011189416600

Clatworthy, J., Hinds, J., \& M. Camic, P. (2013). Gardening as a mental health intervention: A review. Mental Health Review Journal, 18(4), 214-225.

Clift, S. (2012). Creative arts as a public health resource: Moving from practice-based research to evidence-based practice. Perspectives in Public Health, 132, 120-127.

Cloud, W., \& Granfield, R. (2008). Conceptualising recovery capital: Expansion of a theoretical construct. Substance Use and Misuse, 43, 1971-1986.

Corrigan, P. W., Sokol, K. A., \& Rüsch, N. (2013). The impact of self-stigma and mutual help programs on the quality of life of people with serious mental illnesses. Community Mental Health Journal, 49, 1-6. doi: 10.1007/s10597-011-9445-2

Fazel, M., Reed, R. V., Panter-Brick, C., \& Stein, A. (2012). Mental health of displaced and refugee children resettled in high-income countries: risk and protective factors. The Lancet, 379, 266-282. doi: 10.1016/S0140-6736(11)60051-2

Frantz, C. M., \& Mayer, F. S. (2014). The importance of connection to nature in assessing 
environmental education programs. Studies in Educational Evaluation, 41, 85-89. doi: 10.1016/j.stueduc.2013.10.001

Fredriksen-Goldsen, K. I., Emlet, C. A., Kim, H. J., Muraco, A., Erosheva, E. A., Goldsen, J., \& Hoy-Ellis, C. P. (2013). The physical and mental health of lesbian, gay male, and bisexual (LGB) older adults: The role of key health indicators and risk and protective factors. The Gerontologist, 53, 664-675. doi: 10.1093/geront/gns123

Friends of the Earth (2017) How nature saves lives. 22 March 2017. Accessed 17/08/18 http://www.foeeurope.org/how-nature-saves-lives-220317

Glaser, B. G., \& Strauss, A. L. (2009). The Discovery of Grounded Theory: Strategies for Qualitative Research. London: Transaction Publishers.

Gonzalez, M.T., Hartig, T., Patil, G.G., Martinsen, E.W. and Kirkevold, M. (2011). A prospective study of group cohesiveness in therapeutic horticulture for clinical depression. International Journal of Mental Health Nursing, Vol. 20 (2): 119-29.

Greenleaf, A. T., Bryant, R. M., \& Pollock, J. B. (2014). Nature-based counseling: Integrating the healing benefits of nature into practice. International Journal for the Advancement of Counselling, 36, 162-174.

Harbeck, K. M. (2014). Coming out of the classroom closet: Gay and lesbian students, teachers, and curricula. London: Routledge.

Iwata, Y., Dhubháin, Á. N., Brophy, J., Roddy, D., Burke, C., \& Murphy, B. (2016). Benefits of group walking in forests for people with significant mental ill-health. Ecopsychology, 8(1), 16-26.

Joffe, H. (2012). Thematic analysis. In D. Harper and A. Thompson (Eds.) Qualitative Research Methods in Mental Health and Psychotherapy: A Guide for Students and Practitioners. Chichester: Wiley-Blackwell.

Jordan, M. (2009). Nature and Self-An ambivalent attachment? Ecopsychology, 1, 26-31.

Kaplan, R., \& Kaplan, S. (1989). The Experience of Nature: A Psychological Perspective. Cambridge: Cambridge University Press.

Korpela, K. M., Stengård, E., \& Jussila, P. (2016). Nature walks as a part of therapeutic intervention for depression. Ecopsychology, 8(1), 8-15.

Leamy, M., Slade, M., Le Boutillier, C., Williams, J. \& Bird, V. (2011) Conceptual framework for personal recovery in mental health: Systematic review and narrative synthesis. British Journal of Psychiatry, 199, 445-452. doi: 10.1192/bjp.bp.110.083733 
MacInnes, D. L. (2006), Self-esteem and self-acceptance: an examination into their relationship and their effect on psychological health. Journal of Psychiatric and Mental Health Nursing, 13, 483-489. doi: 10.1111/j.1365-2850.2006.00959.x

MacPherson, S., Bird, M., Anderson, K., Davis, T., \& Blair, A. (2009). An art gallery access programme for people with dementia: 'You do it for the moment'. Aging \& mental health, 13(5), 744-752.

Maller, C., Townsend, M., Pryor, A., Brown, P., \& St Leger, L. (2006). Healthy nature healthy people: 'contact with nature' as an upstream health promotion intervention for populations. Health Promotion International, 21(1), 45-54.

Neff, K. (2003). Self-compassion: An alternative conceptualization of a healthy attitude toward oneself. Self and identity, 2(2), 85-101.

Paidas, S. M. (2011). Psychologies of the environment: Searching for themes in the literature. Ecopsychology, 3(2), 125-138.

Parkinson, S., Lowe, C., \& Vecsey, T. (2011). The therapeutic benefits of horticulture in a mental health service. British Journal of Occupational Therapy, 74(11), 525-534.

Peacock, J., Hine, R., \& Pretty, J. (2007). Ecotherapy: The Green Agenda for Mental Health. London: MIND Publications. Retrieved from

https://www.mind.org.uk/media/211252/Ecotherapy_The_green_agenda_for_mental_health_ Executive_summary.pdf

Rappe, E., Koivunen, T., \& Korpela, E. (2008). Group gardening in mental outpatient care. therapeutic communities, 29(3), 273-284

Resnick, S. G., Fontana, A., Lehman, A. F., \& Rosenheck, R. A. (2005). An empirical conceptualization of the recovery orientation. Schizophrenia Research, 75(1), 119-128.

Schuller, T., Bynner, J. \& Feinstein, L. (2004) Capitals and Capabilities. London: Centre for Research on the Wider Benefits of Learning.

Speziale, H. S., Streubert, H. J., \& Carpenter, D. R. (2011). Qualitative Research in Nursing: Advancing the Humanistic Imperative. Lippincott Williams \& Wilkins.

Tan, J. (2010). Grounded theory in practice: issues and discussion for new qualitative researchers. Journal of Documentation, 66, 93-112. doi: 10.1108/00220411011016380

Tew, J. (2011). Social Approaches to Mental Distress. Basingstoke: Palgrave Macmillan. 
Tew, J. (2013). Recovery capital: What enables a sustainable recovery from mental health difficulties? European Journal of Social Work, 16, 360-374. doi:

$10.1080 / 13691457.2012 .687713$

Tong, A., Sainsbury, P., \& Craig, J. (2007). Consolidated criteria for reporting qualitative research (COREQ): a 32-item checklist for interviews and focus groups. International Journal for Quality in Health Care, 19, 349-357. doi: 10.1093/intqhe/mzm042

Topor, A., Borg, M., Di Girolamo, S., \& Davidson, L. (2011). Not just an individual journey: Social aspects of recovery. International Journal of Social Psychiatry, 57, 90-99. doi: $10.1177 / 0020764010345062$

Vining, J. (2003). The connection to other animals and caring for nature. Human Ecology Review, 10, 87-99.

Weare, K., \& Nind, M. (2011). Mental health promotion and problem prevention in schools: what does the evidence say? Health Promotion International, 26(suppl 1), i29-i69. doi: 10.1093/heapro/dar075.

Webber, J., Hinds, J., \& Camic, P. M. (2015). The well-being of allotment gardeners: A mixed methodological study. Ecopsychology, 7(1), 20-28.

White, W., \& Cloud, W. (2008). Recovery capital: A primer for addictions professionals. Counsellor, 9, 22-27.

Wilson, N., Ross, M., Lafferty, K., \& Jones, R. (2009). A review of ecotherapy as an adjunct form of treatment for those who use mental health services. Journal of Public Mental Health, 7, 23-35. doi: 10.1108/17465729200800020

Wilson, N., Jones, R., Fleming, S. Lafferty, K., Knifton, L., Cathrine, K. \& McNish, H. (2011) Branching out: The impact of a mental health ecotherapy program. Ecopsychology, 3, 51-57. doi: 10.1089/eco.2010.0049

Wilson, N., Fleming, S., Jones, R., Lafferty, K., Cathrine, K., Seaman, P., \& Knifton, L. (2010). Green shoots of recovery: the impact of a mental health ecotherapy programme. Mental Health Review Journal, 15(2), 4-14.

Winnicott, D.W. (1965) The maturational process and the facilitating environment. London: Hogarth.

Winnicott, D.W. (1974) Playing and Reality. Harmondsworth: Penguin. 
Mental health recovery and nature - AUTHOR'S ACCEPTED VERSION

World Health Organization (2005) The WHO health impact assessment toolkit for cities. Document 3: how health impact assessment can support decision-making. Copenhagen: WHO Centre for Urban Health. 
Mental health recovery and nature - AUTHOR'S ACCEPTED VERSION

\section{Notes}

${ }^{1}$ Nature-based interventions are also referred to collectively as green care and ecotherapy (Bragg and Atkins, 2016).

${ }^{2}$ See Adams and Jordan (2016) for a more extensive discussion of the reported importance of experiencing nature-based interventions as an escape from mental health service provision.

${ }^{3}$ See for example statements from Public Health England

https://publichealthmatters.blog.gov.uk/2016/11/09/green-space-mental-wellbeing-and-sustainable-

communities/; and the American Public Health Association https://www.apha.org/policies-and-advocacy/publichealth-policy-statements/policy-database/2014/07/08/09/18/improving-health-and-wellness-through-access-to$\underline{\text { nature }}$ 